\title{
Perforin oligomers form arcs in cellular membranes: a locus for intracellular delivery of granzymes
}

\author{
SS Metkar ${ }^{*, 1}$, M Marchioretto ${ }^{2,3}$, V Antonini ${ }^{2}$, L Lunelli ${ }^{2}$, B Wang ${ }^{1}$, RJC Gilbert ${ }^{4}$, G Anderluh ${ }^{5}$, R Roth ${ }^{6}$, M Pooga $^{7}$, J Pardo $^{8}$, \\ JE Heuser ${ }^{6}$, MD Serra ${ }^{2}$ and CJ Froelich ${ }^{\star, 1}$
}

Perforin-mediated cytotoxicity is an essential host defense, in which defects contribute to tumor development and pathogenic disorders including autoimmunity and autoinflammation. How perforin (PFN) facilitates intracellular delivery of pro-apoptotic and inflammatory granzymes across the bilayer of targets remains unresolved. Here we show that cellular susceptibility to granzyme B (GzmB) correlates with rapid PFN-induced phosphatidylserine externalization, suggesting that pores are formed at a protein-lipid interface by incomplete membrane oligomers (or arcs). Supporting a role for these oligomers in protease delivery, an anti-PFN antibody (pf-80) suppresses necrosis but increases phosphatidylserine flip-flop and GzmB-induced apoptosis. As shown by atomic force microscopy on planar bilayers and deep-etch electron microscopy on mammalian cells, pf-80 increases the proportion of arcs which correlates with the presence of smaller electrical conductances, while large cylindrical pores decline. PFN appears to form arc structures on target membranes that serve as minimally disrupting conduits for GzmB translocation. The role of these arcs in PFN-mediated pathology warrants evaluation where they may serve as novel therapeutic targets.

Cell Death and Differentiation (2015) 22, 74-85; doi:10.1038/cdd.2014.110; published online 22 August 2014

The cytotoxic cell granule-secretory pathway depends on perforin (PFN) to deliver granzyme (Gzm) proteases to the cytosol of target cells where they induce apoptosis and other biological effects, such as inflammation. ${ }^{1}$ Ring-shaped transmembrane PFN pores hereafter called 'cylindrical pores', are presumed to act as the gateway for cytosolic entry, either at the plasma membrane or after endocytosis. ${ }^{2-4}$ In either case the highly cationic Gzms are thought to diffuse through these cylindrical pores formed by poly-PFN. Nevertheless, a mechanistic understanding of the phenomenon (how the cationic globular protein exchanges from its carrier proteoglycan, serglycin, to the pore and crosses the plasma and/or vesicular membranes) has been lacking due to limitations in imaging technology and in our detailed understanding of the molecular forms that PFN may adopt following interaction with a target cell plasma membrane.

Here we show under conditions where cylindrical pore formation is minimal, ${ }^{5}$ that granzyme $\mathrm{B}(\mathrm{GzmB})$ translocation readily occurs. We previously demonstrated that a prelude to granzyme translocation is PFN-mediated, Ca-independent phosphatidylserine (PS) externalization (flip-flop) measured by annexin-V and lactadherin binding. ${ }^{6}$ This rapid PS flip-flop also occurs when mouse CD8 cells contact antigen-pulsed target cells. Inasmuch as the proteinaceous cylinders offer a formidable barrier to lipid flow, we have speculated that the observed movement of anionic phospholipids to the external leaflet is due to the formation of proteo-lipidic structures, which consists of oligomerized PFN monomers bearing an arc morphology and plasma membrane lipids. ${ }^{6-8}$

In the work reported here, the topology of PFN embedded into homogeneous planar bilayers and tumor cell plasma membranes was imaged by atomic force microscopy (AFM) and deep etch electron microscopy (DEEM), respectively. Further, the influence of an anti-human PFN mAb (pf-80) that rescues target cells from necrosis, ${ }^{9}$ was examined. The AFM data show that PFN forms arcs as well as rings in planar bilayers, while conductance measurements across equivalent membranes in parallel experiments measured functional pore sizes consistent with these varied structures. The pf- $80 \mathrm{mAb}$ increased the frequency of arc formation and reduced conductance values. Interestingly, PS flip-flop and granzyme delivery were both increased in target cells after PFN oligomerization was interrupted by the pf- $80 \mathrm{mAb}$. A similar effect was seen in T24 bladder carcinoma cells imaged by

${ }^{1}$ NorthShore University Health Systems Research Institute and University of Chicago, Evanston, IL, USA; ${ }^{2}$ Consiglio Nazionale delle Ricerche, Istituto di Biofisica \& Fondazione Bruno Kessler Via alla Cascata 56/C, Trento 38123, Italy; ${ }^{3}$ Center for Integrative Biology CIBIO, University of Trento Via delle Regole, 101 Mattarello (Trento) 38123, Italy; ${ }^{4}$ Division of Structural Biology, Henry Wellcome Building for Genomic Medicine, Oxford, UK; ${ }^{5}$ Laboratory of Molecular Biology and Nanobiotechnology, National Institute of Chemistry, Hajdrihova 19, Ljublana, Slovenia; ${ }^{6}$ Department of Cell Biology and Physiology, Washington University in Saint Louis, 660 S. Euclid Avenue, St Louis, MO, USA; ${ }^{7}$ Institute of Molecular and Cell Biology, University of Tartu, Riia Str 23, Tartu, Estonia and ${ }^{8}$ Department of Biochemistry and Molecular and Cell Biology, Biomedical Research Centre of Aragon (CIBA), IIS Aragon and Nanoscience Institute of Aragon (INA), University of Zaragoza/ARAID Foundation, 50009 Zaragoza, Spain

*Corresponding authors: SS Metkar and CJ Froelich, Department of Medicine, NorthShore University Health Systems Research Institute and University of Chicago, 1001 Univ. Pl., Evanston, IL 60201, USA. Tel: +1 847864 4399; Fax: +1 630627 4231; E-mail: sunilmetkar@gmail.com (SSM) or Tel: +1 8474916448 ; Fax: +1630627 4231; E-mail: E-mail: froelich100@me.com (CJF)

Abbreviations: PFN, Perforin; Gzm, Granzyme; GzmB, Granzyme B; PS, Phosphatidylserine; AFM, Atomic force microscopy; DEEM, Deep etch electron microscopy; $\mathrm{PI}$, Propidium iodide; BAPTA-AM, 1,2-bis(o-aminophenoxy)ethane-N,N,N',N'-tetraacetic acid; POPC, 1-palmitoyl-2-oleoyl-sn-glycero-3-phosphocholine; MAC, Membrane attack complex; CDCs, Cholesterol dependant cytolysins; MACPF, Membrane attack complex proteins of complement and perforin; CPP, cell-penetrating peptides; GPMVs, Giant plasma membrane vesicles

Received 28.3.14; revised 01.7.14; accepted 03.7.14; Edited by G Salvesen; published online 22.8.14 
DEEM. Treatment with PFN leads to deposition of rings (barrel stave pores) and arcs and the pf- $80 \mathrm{mAb}$ increased the ratio of arcs to rings on the surface of these cells. We suggest that the observed protein arcs function as toroidal pores in whole cells, explaining PS flip-flop, and act as focal points for granzyme translocation across lipid bilayer.

\section{Results}

Perforin causes minimal membrane alterations in targets destined to undergo Granzyme B mediated apoptosis. The X-ray crystal structure of monomeric mouse PFN has been solved, and a structure for the pores it forms has been determined using cryo-electron microscopy. These studies have shown how oligomerisation of PFN monomers leads to the formation of a cylindrical pore with an internal diameter of $15-20 \mathrm{~nm},{ }^{2,7}$ sufficient for the passage of a granzyme molecule given its hydrodynamic size $($ GzmB $-4.3 \mathrm{~nm}){ }^{6}$ However, using a protocol that detects transmembrane pore formation by streptolysin $\mathrm{O}$ (propidium iodide (PI) uptake by flow cytometry), ${ }^{10,11}$ we do not observe functional evidence of similar-sized structures when PFN is used at concentrations that coincide with granzyme translocation and apoptotic cell death. ${ }^{5,6}$ This suggests that GzmB delivery may not involve cylindrical pores, but instead some other mechanism.

Since we failed to detect PFN-mediated membrane permeabilization with $\mathrm{PI}$, we sought to verify whether $\mathrm{Ca}^{2+}$ influx earmarked target cells that succumb to GzmB. Previous data have suggested that a $\mathrm{Ca}^{2+}$-dependent membrane repair response could be linked to the endocytosis of GzmB, as part of the gigantosome model of endosome-mediated GzmB delivery into cells. ${ }^{4}$ Subsequent passage to the cytosol (presumably through ring-like pores) is then thought to enable the granzymes to elicit cell death. ${ }^{12}$ Here, using a modified quantitative flow-based approach to measure $\mathrm{Ca}^{2+}$ flux at the single cell level, ${ }^{13}$ we show that non-necrotic target cells that became apoptotic in the presence of GzmB show rapid $\left(<15 \mathrm{sec}\right.$ ) albeit minimal $(70-120 \mathrm{nM}) \mathrm{Ca}^{2+}$ influx (Figures 1a and b; Figures $3 b$ and $c$ ). Importantly, 1,2-bis (o-aminophenoxy)ethane-N,N,N',N'-tetraacetic acid, (BAPTA$\mathrm{AM})$, an intracellular $\mathrm{Ca}^{2+}$ chelator, did not modify susceptibility to GzmB-induced apoptosis. ${ }^{6}$ Furthermore, a sustained cell surface half-life of immunoreactive PFN was observed on these PI negative cells ( $>15 \mathrm{~min}$ ) whereas GzmB was rapidly cleared (Figure 1c). Using sensitive apoptosis markers such as mitochondrial membrane depolarization, cell death was noted when GzmB was added as long as $15 \mathrm{~min}$ after PFN exposure (see Supplementary Figure S1 for supporting data). Taken together, unlike rapidly cleared cylindrical pores, these data indicate that PFN generates other membrane perturbations that facilitate GzmB delivery.

Anti-Perforin antibody, pf-80, augments PS flip-flop and GzmB-induced apoptosis. Since $\mathrm{Ca}^{2+}$ influx is not a dependable indicator for GzmB-induced apoptosis, we evaluated other biochemical events that might allow their identification. Unexpectedly, PFN was found to induce very
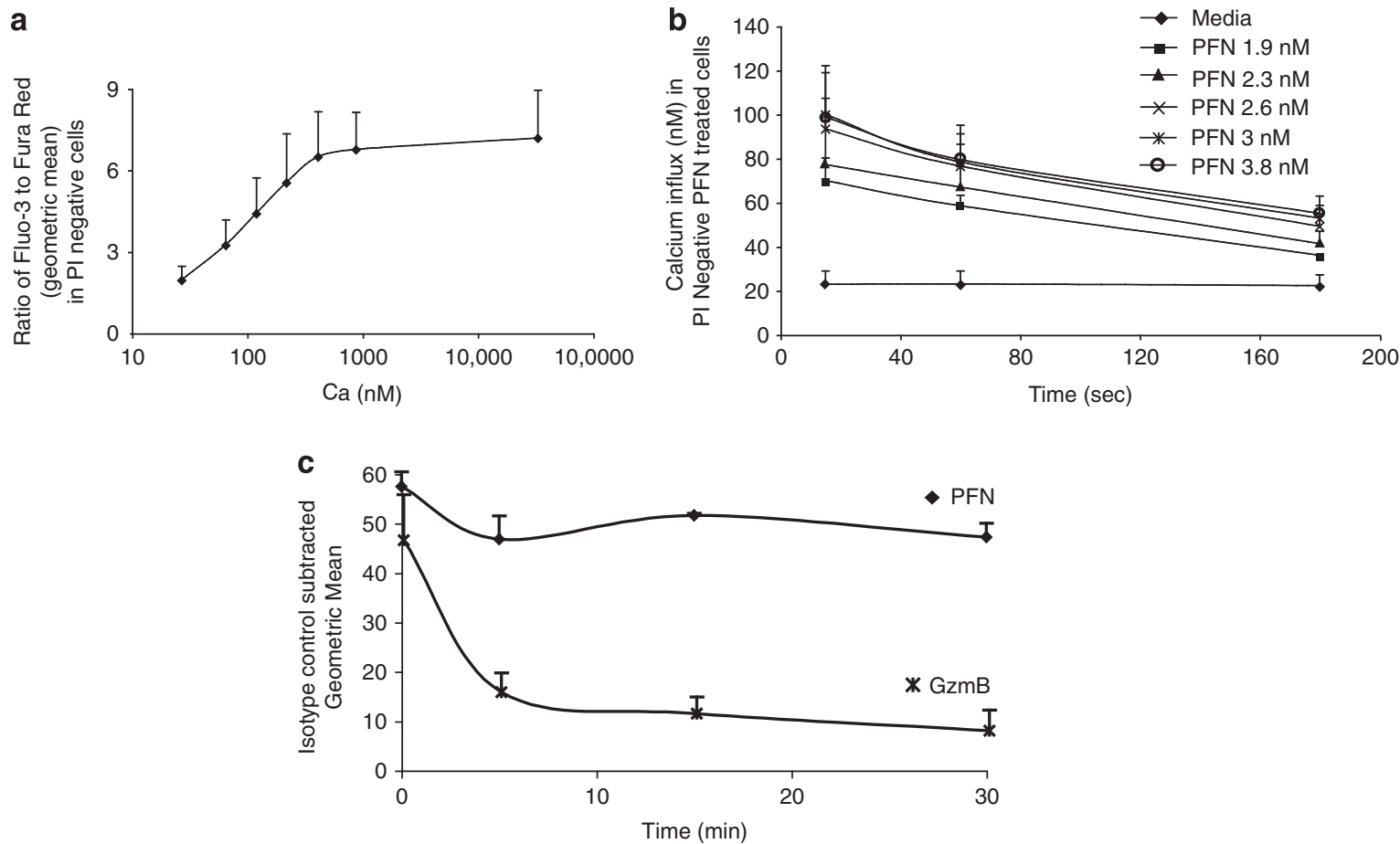

Figure 1 PFN treated cells that deliver GzmB lack signs of membrane damage and show minimal $\mathrm{Ca}^{2+}$ influx. (a) Calibration of $\mathrm{Ca}^{2+}$ influx by flow cytometry. Standardization performed as described in methods. ${ }^{43}$ Values plotted against free $\left[\mathrm{Ca}^{2+}\right]$, (mean + S.D., $\left.n=4\right)$. (b) Minimal $\mathrm{Ca}^{2+}$ influx occurs in PFN-treated, PI negative cells. Fluo-3 and Fura Red loaded Jurkat cells were treated with indicated concentrations of PFN in the presence of PI and intracellular $\mathrm{Ca}^{2+}$ flux (nM) was measured in the PI negative subset using the $\mathrm{Ca}^{2+}$ calibration curve from (a); $(n=4$; mean + S.D.). (c) GzmB but not PFN is cleared rapidly from the cell surface. Jurkat cells were treated with PFN $\left(7.6 \mathrm{nM}\right.$, in presence of $\left.0.2 \mathrm{mM} \mathrm{Ca}{ }^{2+}\right)$ or GzmB $(1.92 \mathrm{nM})$ for $30 \mathrm{~min}$ on ice, washed, chased at $37^{\circ} \mathrm{C}$ for the times indicated and stained. Isotype control subtracted mean fluorescence intensity (MFI, geometric mean) of GzmB or PFN binding on PI negative cells was plotted against the time of chase at $37^{\circ} \mathrm{C}$ (MFI $+\mathrm{S} . \mathrm{D} ., n=3$ ) 


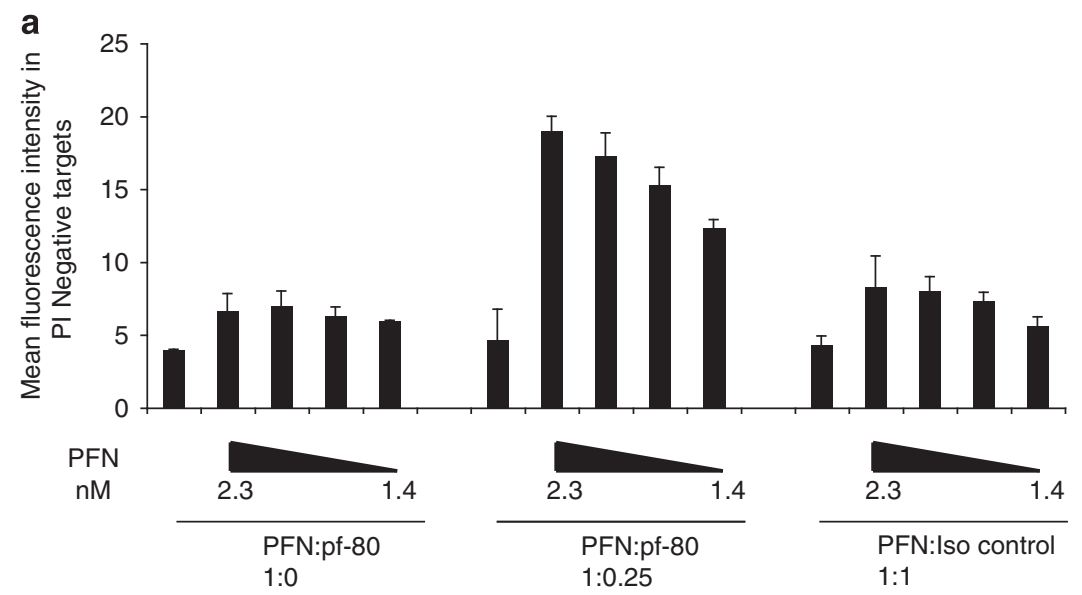

b

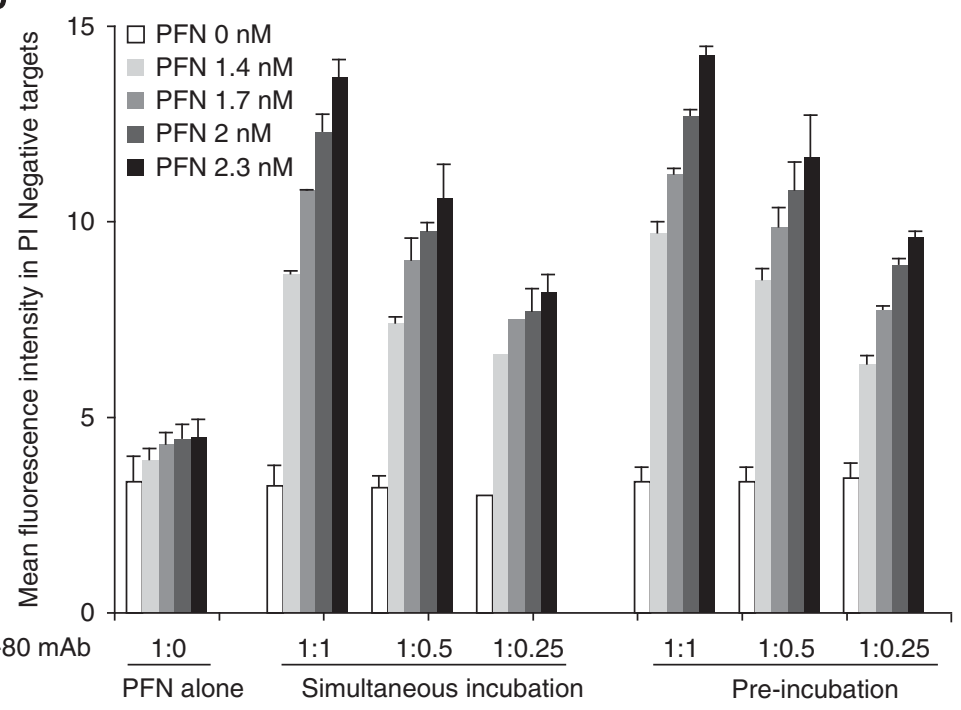

c

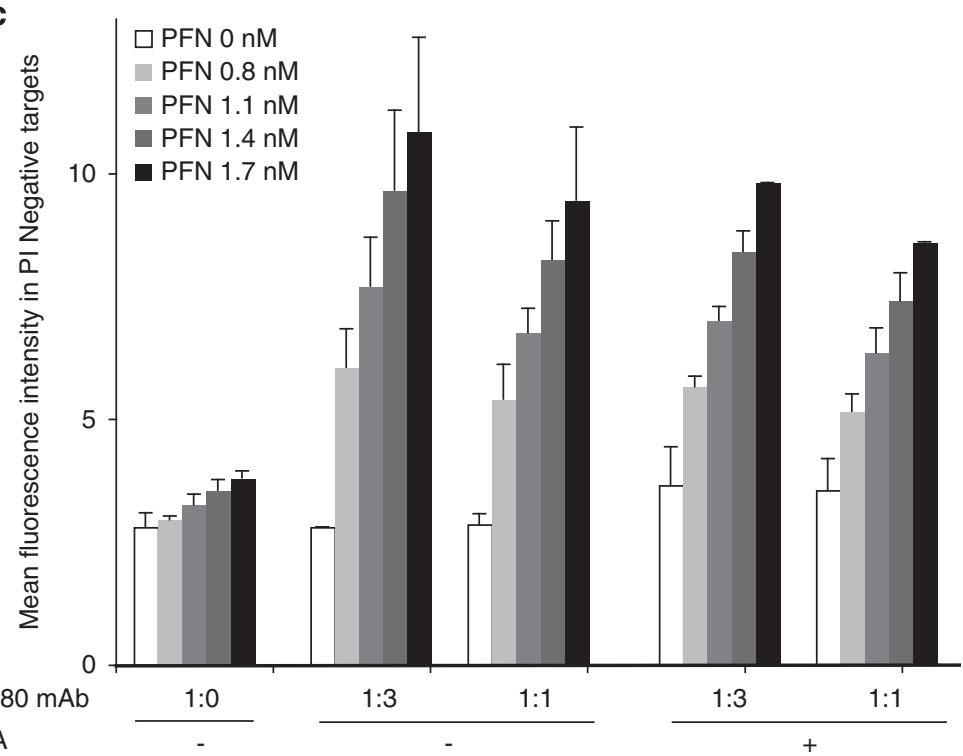


rapid phosphatidylserine (PS) translocation (flip-flop) in target cells even though the integrity of the plasma membrane is not compromised. ${ }^{6}$ Based on these data we speculated that PFN, besides appearing as cylindrical pores, could form arcs at the concave interface of PFN oligomers and membane phospholipids. ${ }^{8}$ These structures would most likely exist when PFN is applied at concentrations that increase rapid PS flip-flop rate encouraging granzyme delivery without causing necrotic cell death. ${ }^{5}$

Due to the instability of PFN, a major impediment to its study in vitro is the capacity to reproducibly achieve concentrations that maximize granzyme delivery (and its dominate endpoint apoptosis) yet minimize necrosis. Throughout a wide range of concentrations, the presence of a variable percentage of necrotic cells complicate data analysis. This is especially problematic for imaging studies that cannot incorporate a marker for permeabilized cells or for experiments in which the necrotic cells are difficult to remove (e.g. immunoblotting of detergent lysed target cells). Therefore,we developed a technique that reduces cylindrical pore formation in either PFN-treated target cells or lipid bilayers.

The anti-PFN mAb, pf-80, recognizes a conformational epitope that inhibits PFN-mediated plasma membrane damage in target cells. ${ }^{9}$ Because this $\mathrm{mAb}$ does not interfere with binding of PFN to the plasma membrane, ${ }^{14}$ we hypothesized that the antibody might reduce necrosis while, at the same time, preserve or increase the subset of cells susceptible to GzmB. If so, then immunoreactive PFN would be detectable on these cells. Complexes between PFN and pf-80 mAb were measured on PI-negative target cells when the PFN monomer was added to pf- $80 \mathrm{mAb}$ at a molar ratio of 1-0.25 (Figure 2a). To confirm that pf- $80 \mathrm{mAb}$ did not interfere with binding, PFN was preincubated with the pf-80 mAb before adding cells. The intensity of the signal was comparable to the simultaneous addition of PFN and pf-80 mAb (Figure 2b). To assess the interaction of the mAb with stably inserted PFN monomers, we also asked whether PFN $\sim$ pf-80 complexes were eluted by $\mathrm{Ca}^{2+}$ chelation. As shown in Figure 2c, EGTA did not reduce the immunoreactivity on the surface of the PI-negative target cells.

Since pf- 80 mAb remains bound to target cell-associated PFN and there was no clear evidence of membrane permeabilization by cylindrical pores, we speculated that the $\mathrm{mAb}$ interrupts monomer oligomerization to cylindrical pores. Varying the molar ratio of pf-80 mAb to PFN monomer should then influence the intensity of PFN-mediated necrosis. Indeed, with increasing concentrations of pf-80 mAb, PFNmediated target cell necrosis was drastically reduced (Figure 3a, top panel). Compared to PFN alone, the addition of pf-80 mAb to PFN enhanced PS flip-flop (PFN:pf-80, 1:0.25 and 1:0.5) (Figures 3a, bottom panel) and this correlated with increased GzmB delivery as monitored by caspase-3/7 activation (Figures $3 \mathrm{~b}$ and $\mathrm{c}$ ). At a higher ratio of PFN to pf-80 (1:1), both PS flip-flop (Figure 3a, lower panel) and caspase-3/-7 activities (Figures $3 \mathrm{~b}$ and $\mathrm{c}$ ) declined. These data support the notion that the pf-80 mAb encourages deposition of limited numbers and/or sizes of oligomerized structures on the target cell plasma membrane and that this outcome is associated with both increased PS flip-flop and GzmB delivery activities. Most strikingly, the presence of pf-80 (at a PFN:pf-80 ratio of $1: 0.25$ ) not only reduces necrosis (and therefore the permeabilisation of the cell envelope) but increases the effectiveness with which GzmB is delivered to trigger apoptosis.

pf-80 mAb augments the number of functional arcs in PFN treated planar bilayers. To identify whether pf-80 $\mathrm{mAb}$ treatment permitted the formation of limited PFN oligomers on the membrane, we visualized the topology of the deposited structures by atomic force microcopy (AFM) using PFN-treated planar bilayers composed of 1-palmitoyl2-oleoyl-sn-glycero-3-phosphocholine (POPC). In the presence of PFN alone, $70 \%$ of the structures were complete rings having a diameter of $21.7 \pm 2.8 \mathrm{~nm}$ and a height of $11.8 \pm 0.4 \mathrm{~nm} \quad(n=7)$ (total number of rings considered was 87) (Figures $4 a-c$ ). Incomplete rings (arcs) were observed in $25 \%$ of the cases (Figure $4 a$, white arrowheads). Additional fields treated with PFN alone are shown in Figures $4 d$ and $e$, while a magnified image from Figure $4 \mathrm{e}$ is shown in Figure 4f. When the POPC bilayer was exposed to a combination of PFN and the pf- $80 \mathrm{mAb}$, a clear increase in the number of arcs is observed (Figures $4 \mathrm{~g}$ and $\mathrm{h}$ ). A magnified image is shown in Figure 4i. Figure 4j summarizes the imaging data for the AFM experiments showing statistically significant differences in the ratio of rings to arcs: 75 to 25 without pf- 80 and $43-57$ in presence of a $1 x$ molar excess of pf- $80 \mathrm{mAb}$.

The rings and arcs appear to possess similar radii of curvature (supporting evidence in Supplementary Figure S2). This suggests that an arc may represent a transtitional state that expands to a complete ring, an outcome dictated by the multiple factors that regulate monomer oligomerization. Both structures, arc and cylindrical pore, have comparable projection heights above the membrane plane and the oligomers do not collapse for membrane insertion to progress. ${ }^{15} \mathrm{We}$ therefore propose that an arc and cylindrical pore both proceed by assembly of the growing arc. Similar to membrane attack complex (MAC), each monomer added to a growing arc is optimally positioned as it unfurls and inserts two hairpins into the membrane.

To examine the functionality of these arcs, we measured their conductance in planar lipid membranes. PFN single

Figure 2 Anti-PFN mAb, pf-80, can be detected on target cell surface complexed with PFN. (a) pf-80 mAb can be detected on target cell plasma membranes complexed with PFN. Jurkat were treated with PFN (0-2.3 nM) in absence or presence of pf-80 ( 0.25 fold molar excess) or an isotype control antibody ( 1 fold molar excess), washed and stained with an Alexa 488 tagged anti mouse secondary antibody. Fluorescence signal in PI negative cells was analyzed, $(n=3, \mathrm{M}+\mathrm{S} . \mathrm{D}$.). (b) pf-80 does not interfere with binding of PFN. PFN (0-2.3 nM) was either co-incubated with pf-80 ( 0.25 to 1 fold molar excess; simultaneous incubation) and Jurkat or pre-incubated with pf-80 alone for $15 \mathrm{~min}$ at room temperature followed by introduction of cells. After $10 \mathrm{~min}$, cells were washed and stained with Alexa 488 tagged anti-mouse secondary antibody $(n=3$; mean + S.D.). (c) Membrane bound PFN:pf-80 complexes are not eluted by EGTA. PFN (0 to $1.7 \mathrm{nM}$ ) was pre-incubated with pf-80 (1 and 3 fold molar excess) for 15 min followed by introduction of cells. After $10 \mathrm{~min}$, cells were washed in presence or absence of EGTA $(5 \mathrm{mM})$, stained with Alexa 488 anti-mouse antibody and fluorescent signal in PI negative cells analyzed. $(n=3$, mean + S.D. $)$ 
channel conductances were widely distributed with a mean value of about $3 \mathrm{nS}$ (Figure 5a), similar to the values observed previously. ${ }^{16}$ The pf-80 mAb shifts conductance values downward, suggesting that a population of smaller channels is increased (Figure $5 \mathrm{~b}$ ). Interestingly, the pf- $80 \mathrm{mAb}$ reduced the presence of gradual increases in conductance (Figure $5 \mathrm{c}$ ). Discrete steps in current flow are related to the opening of ion conducting paths, which could be attributed to complete cylindrical pores or to arcs that have reached their minimum dimension for ion flux. Growing arcs would then explain the observed gradual increases in current, as opposed to single step-like increments. Accordingly, pf-80 mAb recognizes and is able to bind to arcs but not encircled PFN oligomers (i.e., the complete cylindrical ring) blocking their growth to either larger arcs or full rings. The pf- $80 \mathrm{mAb}$ thus seems to interact with the subunit interface of the growing PFN oligomers to increase the proportion of low-caliber structures. These data indicate the following: (i) arcs have functional conductive paths; (ii) a minimum dimension is necessary for arcs to display measurable conductance (see Supporting Supplementary Figure S3 for further explanation); and (iii) the pf-80 mAb appears to inhibit cylindrical pore formation resulting in smaller arcs and thus smaller conductive paths.

pf-80 mAb augments the number of arcs on plasma membrane of PFN-treated target cells. Since the observed protein arcs may be preferred among loosely composed, homogeneous phospholipids, it was crucial to test whether oligomerization to limited arc structures could also be observed when PFN was added to the topologically more complex plasma membrane. We imaged PFN structures on the surface of the bladder carcinoma cell line, T24, using DEEM either in the presence or absence of the pf-80 $\mathrm{mAb}$. PFN titration revealed that $200 \mathrm{ng} / \mathrm{ml}(3 \mathrm{nM})$ yielded about $60-70 \%$ high PI positive, necrotic cells. As expected, the pf-80 mAb markedly protected the cells from necrosis. At a 1:3 molar ratio (PFN to pf-80), the level of necrotic cells fell from $70 \%$ to baseline levels. To aid the imaging of PFNphospholipid interactions by DEEM, tumor cells were briefly pre-fixed with paraformaldehyde and then treated with PFN (200 ng/ml - 3nM). Here, PFN alone generated an average of 70 rings and 30 arcs per field (Figure 6a). The external diameter of the rings ranged from 19-34 $\mathrm{nm}$. In presence of the pf-80 mAb, there was an increase in the number of arcs and a concomitant reduction in the number of rings (Figure $6 b$ ), with the ratio of rings:arcs shifting to $30: 70$ (summarized in Figure 6c). Glutaraldehyde pre-fixed cells were similarly influenced by pf-80 exposure (Supporting Supplementary Figures $\mathrm{S} 4 \mathrm{a}-\mathrm{C}$ ).

\section{Discussion}

Structural and biophysical studies have established that oligomerized PFN monomers form cylindrical pores measuring approximately $20 \mathrm{~nm} .^{2}$ This structure has seemed the obvious candidate for providing granzyme passage into a target cell cytosol. Perplexingly, however, PFN efficiently induces translocation of GzmB in targets that exclude even low molecular weight cationic fluorophores, $5,6,17,18$ suggesting that cylindrical pores are somehow dispensable for granzyme delivery leaving another form of PFN responsible.

In addition to forming cylindrical structures, the present data show that PFN monomers also undergo limited oligomerization to protein arcs (defined by AFM and DEEM imaging techniques) which can be considered toroidal pores (defined by lowered ionic conductance and anionic phospholipid flip-flop). ${ }^{19,20}$ In contrast to a cylindrical pore which is lined exclusively by protein that barricades phospholipid movement across the bilayer, ${ }^{21,22}$ a toroidal pore (alternately termed proteolipid, lipidic or 'leaky slit' pore) consists of inserted peptides (or proteins) and lipid together forming a water channel. During the formation of such structures, transbilayer curvature is promoted leading to merger of the inner and outer leaflets. The fusion of the two as well as the formed water channel then encourage anionic phospholipids (e.g., PS) to migrate to the outer leaflet (the flip-flop phenomenon).

An increasing number of reports have shown that peptides form toroidal pores. Examples include: (1) Melittin, the principal component of bee venom; ${ }^{23}$ (2) Magainin, an antimicrobial peptide; ${ }^{24}$ (3) sticholysin II, ${ }^{25}$ equinatoxin II, ${ }^{26}$ pore forming toxins from sea anemone and pneumolysin; ${ }^{27}$ (4) Colicin E1, a bacteriocin; ${ }^{28}$ and (5) Bax. ${ }^{29}$ Whether cytolytic proteins generate these structures is uncertain. However, recent data suggest that truncated forms of alpha-hemolysin have the capacity to form toroidal pores. ${ }^{30}$ This controversy is encouraged by the proposed mechanism that cylindrical pore formation universally involves transition from a pre-pore to transmembrane pore configuration. ${ }^{31}$ In this case, the pre-pore operationally serves as the proto-assemblage where a ring of monomers binds to the bilayer and then insert en masse to create the cylindrical pore. In the face of this model, the formation of an arc is seemingly problematic. However, ultrastructural imaging indicates that many cholesterol dependant cytolysins (CDCs) produce arcs as well as rings. ${ }^{8}$ Concentrations of studied CDCs are selected basis that they form cylindrical pores. A primary concern therefore is whether these concentrations are always biologically relevant and that arc formation may instead be prevalent when the cytolysins are examined under physiological conditions. The paradigm we describe here for PFN may therefore be generalizable to many other Membrane attack complex proteins of complement and perforin family (MACPF) as well as CDCs if examined at biologically relevant concentration in vitro.

We have shown that pf-80 recognizes a conformational epitope and likely interacts with a region that participates in oligomerization of the monomers., 92 Since PFN $\sim$ pf-80 complexes are detected on non-permeabilized target cell surface, the antibody is predicted to interfere with PFN oligomerization by capping an enlarging oligomer before it forms a cylindrical pore. Phenotypically, this translates to the anticipated blockade of cylindrical pore formation in simple planar bilayers and complex plasma membrane where functionality of an arc is defined respectively by measurable conductance and PS flip-flop. ${ }^{20}$ Notably, during the AFM experiments, pf-80 mAb increases the total number of structures. This outcome is consistent with the formation of twenty-mer cylindrical pores in the absence of pf- 80 but of arcs varying in size between 6 to 10 mer in the presence of the 
a

PFN:pf-80

PFN:Isotype

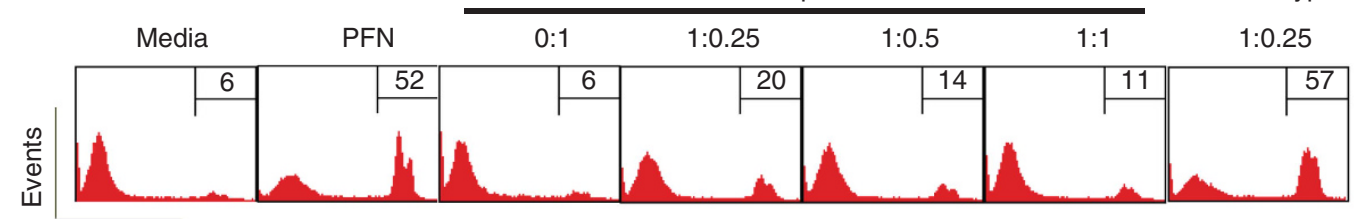

Propidium lodide

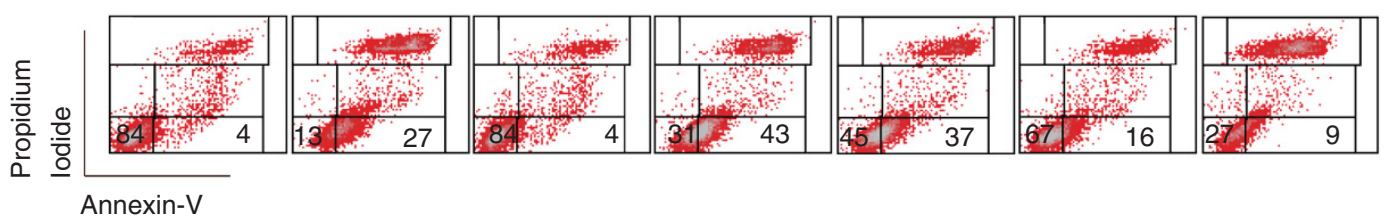

b
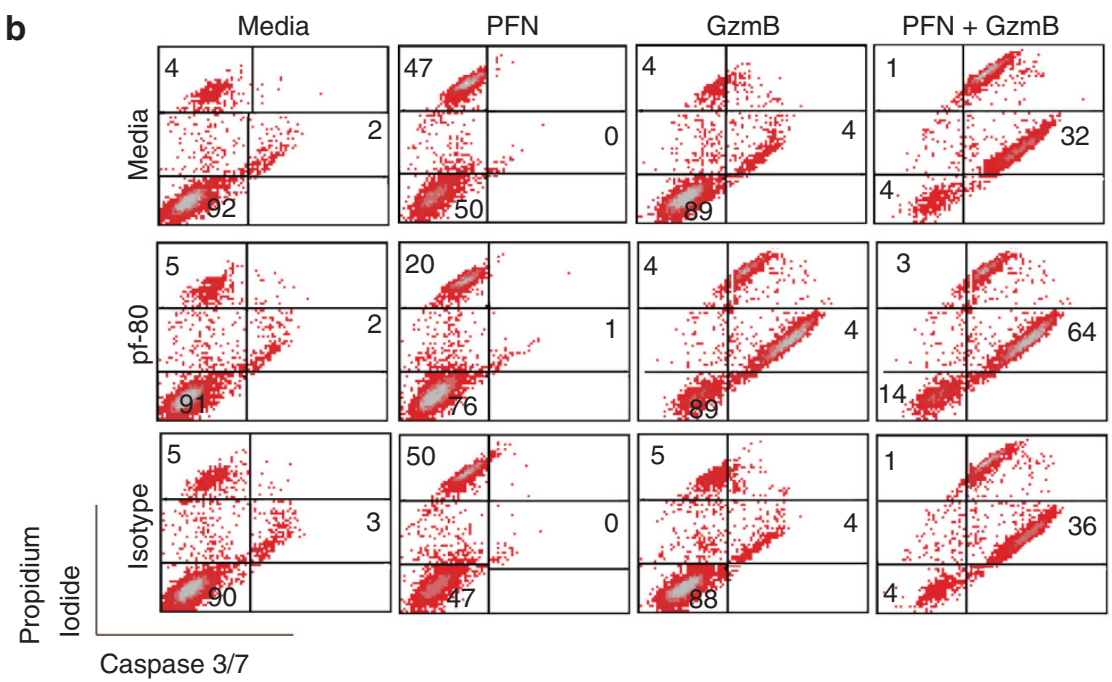

c

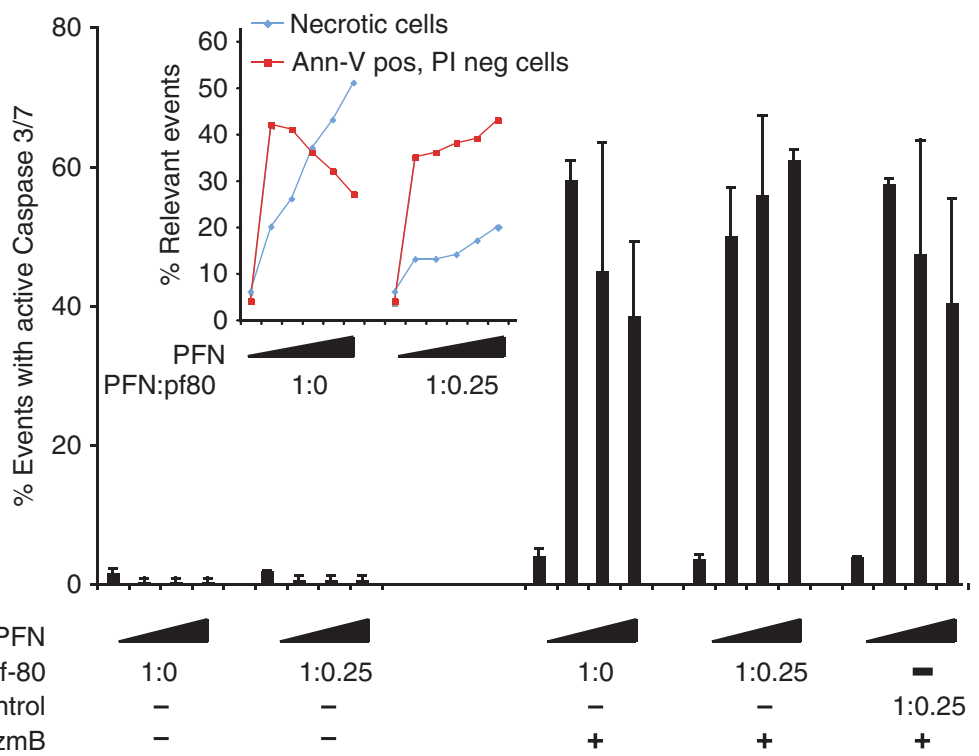

Figure 3 Anti-PFN mAb, pf-80 blocks PFN mediated necrosis but enhances PS flip-flop and GzmB delivery. (a) pf-80 mAb blocks PFN mediated necrosis but enhances PS flip-flop. Cells were treated with PFN $(1.97 \mathrm{nM}) \pm \mathrm{pf}-80 \mathrm{mAb}$ in varying molar ratios. PI was present throughout and measured necrotic events defined as PI Hi events (top panel). PS flip-flop (bottom panel), was measured under identical conditions, shown as \% events in the lower right quadrant of the FACS dot plot. Isotype matched Ab served as a control (representative figure from one of three studies). (b) pf-80 mAb augments PFN-mediated GzmB delivery. Jurkat cells were treated with PFN alone (1.97 nM), GzmB alone $(1 \mu \mathrm{g} / \mathrm{ml})$ and PFN plus GzmB \pm 0.25 molar excess of pf- $80 \mathrm{mAb}$ or isotype control for $1 \mathrm{~h}$ at $37^{\circ} \mathrm{C}$. Pl and caspase $3-7$ activity were analyzed at $1 \mathrm{~h}$. Values in mid-right gate show caspase 3-7 activation and a representative figure from one of three studies is shown. (c) Summary. PFN concentrations ranged from 0 to $1.97 \mathrm{nM}$ for the necrosis and PS flip-flop experiments (inset) and from 0 to $2.1 \mathrm{nM}$ for caspase 3-7 activation. GzmB was at $1 \mu \mathrm{g} / \mathrm{ml}(n=3$, mean + S.D.) 
PFN (15.2 nM)
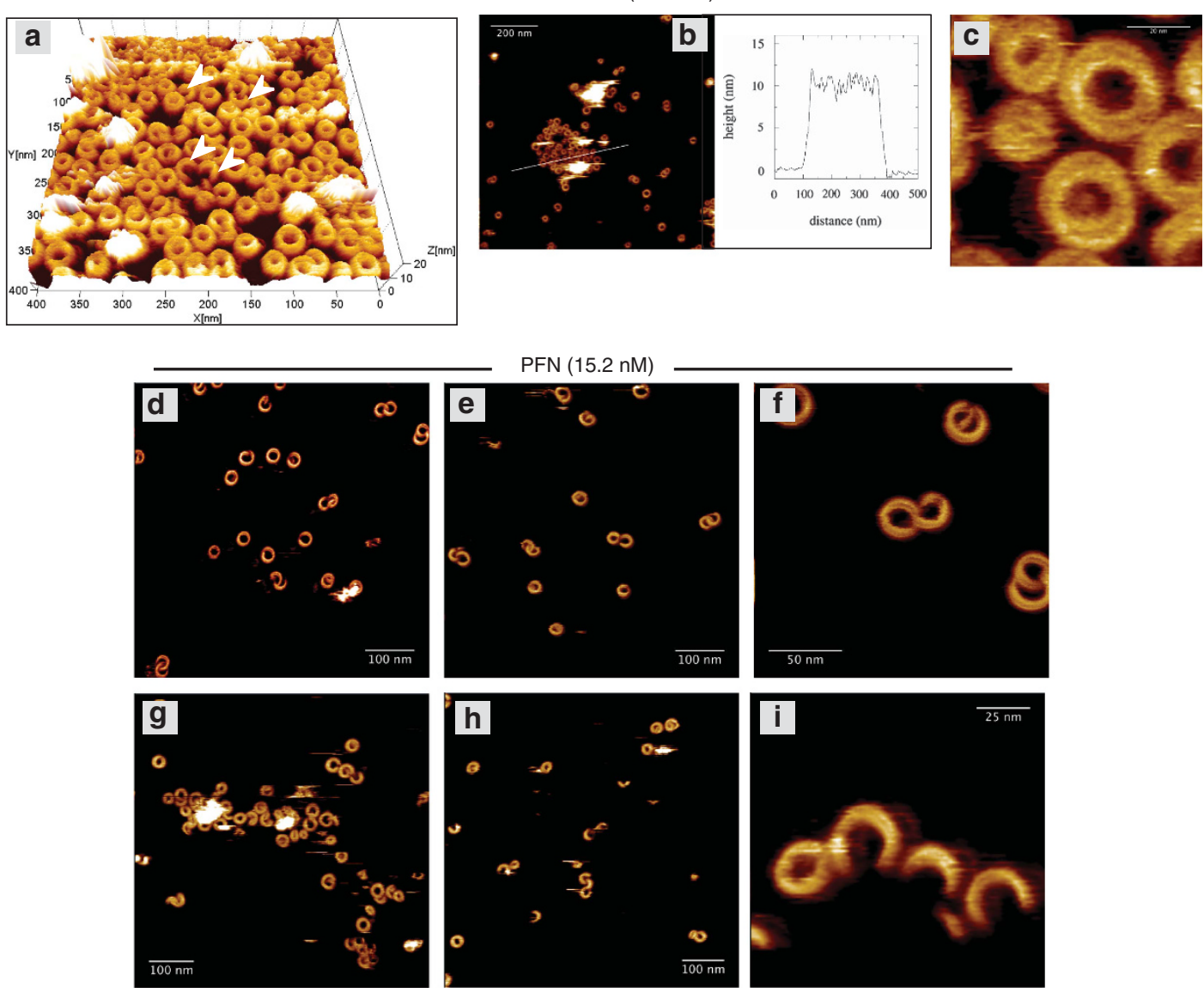

PFN (15.2 nM) + pf-80 (3.8 nM)

PFN (15.2 nM) + pf-80 (7.6 nM)

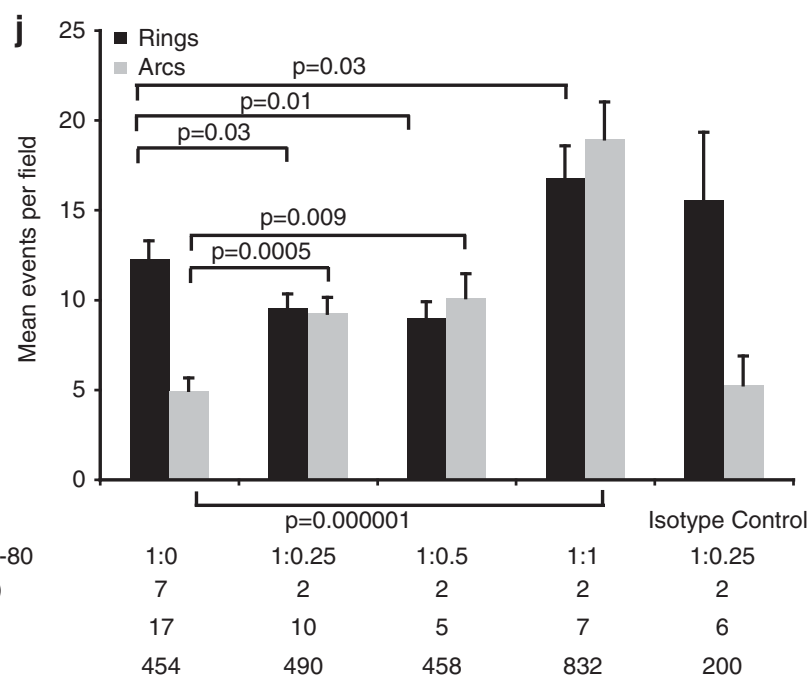

Figure 4 The anti-PFN mAb, pf-80, augments the number of incomplete pores/arcs in PFN treated POPC bilayers. (a-f) Imaging of structures formed by PFN on planar bilayers using AFM. (a) PFN (15.2 nM) was added (15 min) at RT to POPC planar bilayer adhered to mica and imaged in tapping mode. Rings were usually $22 \mathrm{~nm}$ in diameter; arcs are also shown (arrowheads); (b) A field with lower protein density is shown here height profile extends $12 \mathrm{~nm}$ above the bilayer. (c) A magnified image from a small region of (a) demonstrates uniform sized pores $(22 \mathrm{~nm})$ and smaller rings. Images are from two out of seventeen different fields (7 experiments). (d-f) Mica adhered POPC planar bilayer was treated with PFN alone (15.2 $\mathrm{nM})$. (g-i) Imaging of structures formed by PFN in presence of pf-80. PFN (15.2 $\mathrm{nM}$ ) added to bilayer with $0.25 \times(\mathbf{g})$ or $0.5 \mathrm{x}(\mathrm{h})$ molar excess of pf- $80 \mathrm{mAb}(3.8 \mathrm{and} 7.6 \mathrm{nM}$ ) for $15 \mathrm{~min}$ at RT. The height of structures, primarily arcs, is in the range $10-12 \mathrm{~nm}$. i. A magnified image depicting arcs is shown where pf-80 was used at a 1:0.5 molar ratio. Images are representative for one of 10 fields from two experiments. (j) Summary: the number of rings and arcs for PFN:pf- 80 molar ratios from 1:0-1:1 with PFN constant at 15.2 nM (mean + S.D.) are shown. Isotype matched antibody used as described in Figure 1. The number of experiments (n) for each condition, the number of fields and the total number of events analyzed are indicated. A paired t-test (2-tailed with two sample unequal variance) was utilized to measure statistical significance 

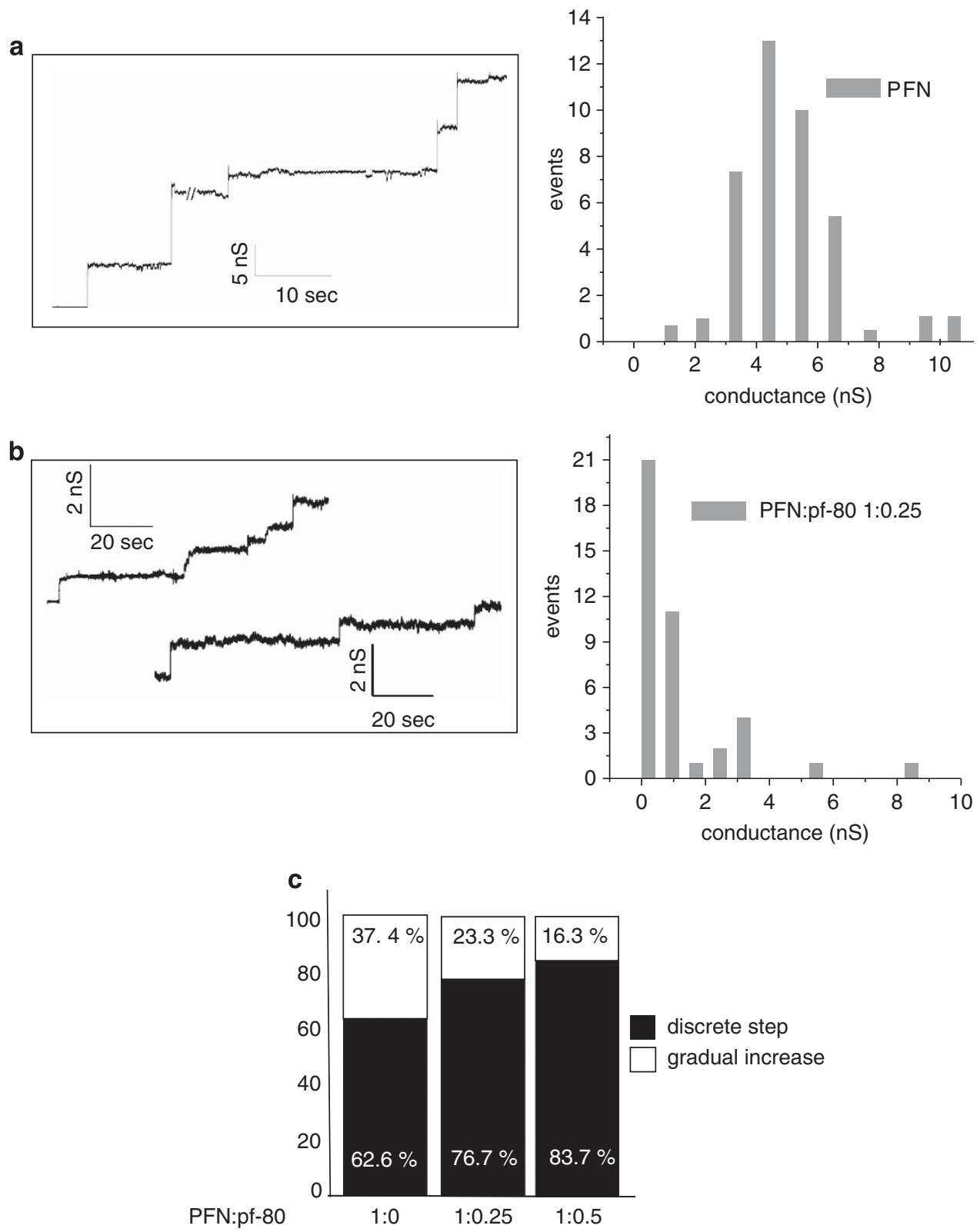

Figure 5 Effects of pf-80 mAb on single channel conductance values mediated by PFN. (a) Conductance distribution of PFN channel. Planar lipid membranes (PLM) consisting of POPC/cholesterol (1/1 mol) were treated with PFN as indicated in the absence of mAb pf-80. (b) Conductance distribution of PFN channel in the presence of $\mathrm{mAb}$ pf-80. PLM were treated with PFN as indicated in presence of pf-80 at 1:0.25 molar ratio. Representative current traces are shown on the left. (c) Summary. Discrete versus continuous increase in conductance is shown. PFN was used at $15.2 \mathrm{nM}$ and pf-80 at $3.8 \mathrm{nM}$ (ratio of 1:0.25) and $7.6 \mathrm{nM}$ (ratio of 1:0.5)

mAb. Nevertheless, while PFN pf-80 complexes were detectable on target cells using a flow based method, the presence of the mAb was not apparent by AFM and DEEM imaging. While the explanation for this discrepancy is uncertain, it is clear that the anti-PFN mAb acts to rescue target cells from cylindrical pore overload revealing a marked increase in membrane arcs.

What is the mechansim underlying the passage of GzmB through the PFN-induced arc structures? Translocation of GzmB across a PFN-induced arc may resemble the action of cell-penetrating peptides (CPP). The latter penetrate into cells directly across the plasma membrane ${ }^{33,34}$ as well as induce endocytic uptake. Remarkably, penetration of CPPs is augmented by externalized PS, an effect further increased by depleting membrane cholesterol. ${ }^{35}$ Since the exposure of $\mathrm{PS}$ on the plasma membrane is associated with PFN arcs and the latter are stabilized if cells are depleted of cholesterol, ${ }^{6}$ we asked whether GzmB penetrates similar biological membranes. Although GzmB has a $\mathrm{Mr}$ of approximately $32 \mathrm{kDa}$, which is $10-20$ fold higher than typical CPPs, the fluorescently labeled granzyme accumulated in giant plasma membrane vesicles (GPMVs). These vesicles are surrounded by a plasma membrane and filled with cell cytoplasm (see Supplementary Figure S5 for supporting data). GzmB translocates into GPMVs more slowly than CPPs. ${ }^{35}$ Nevertheless, accumulation of the labeled granzyme 

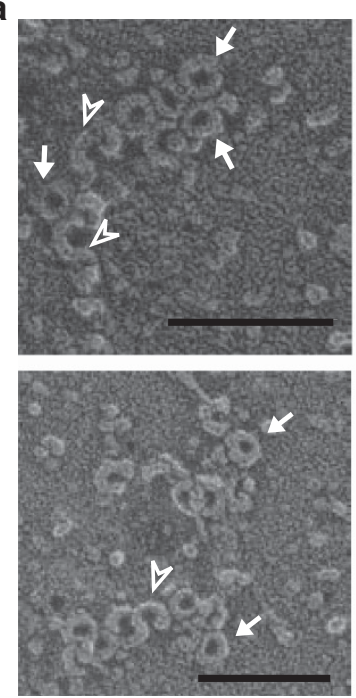

b
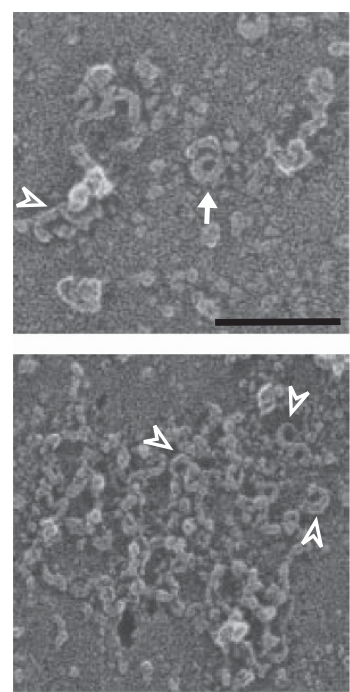
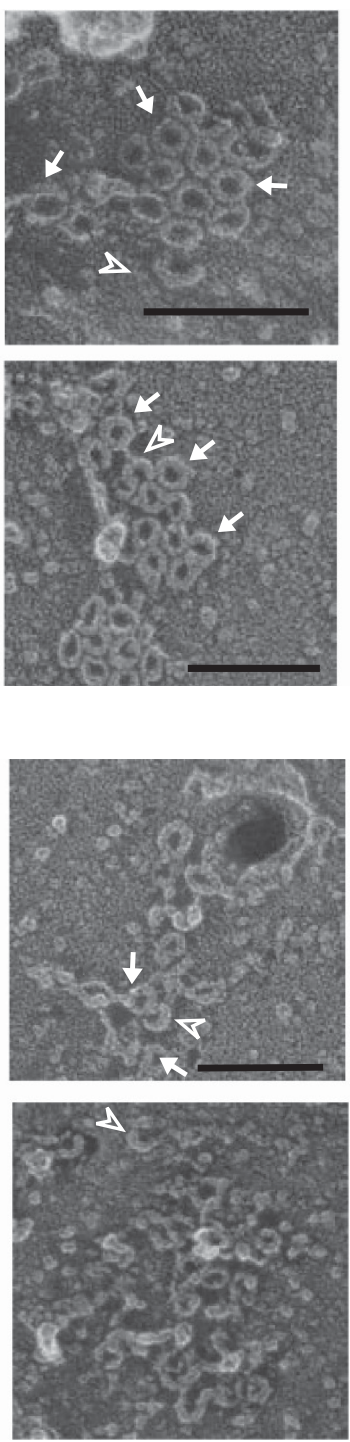
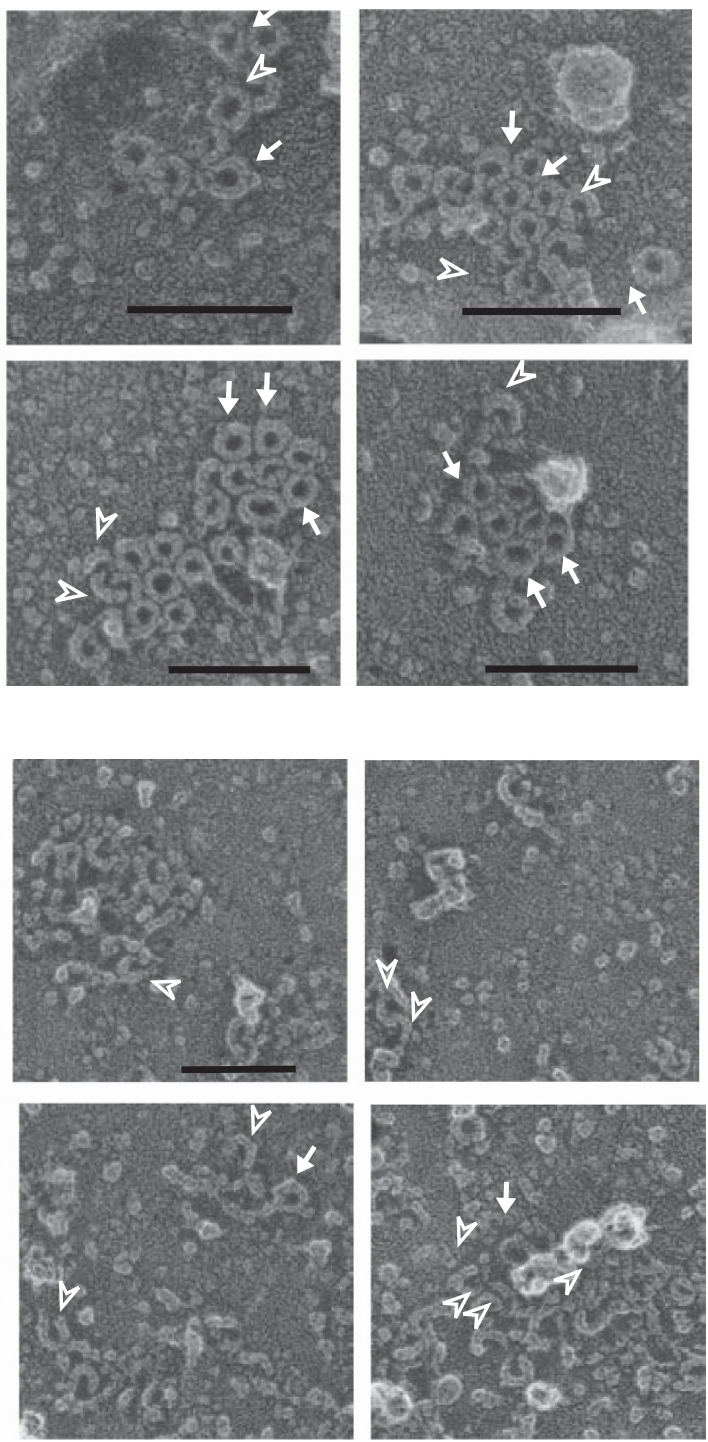

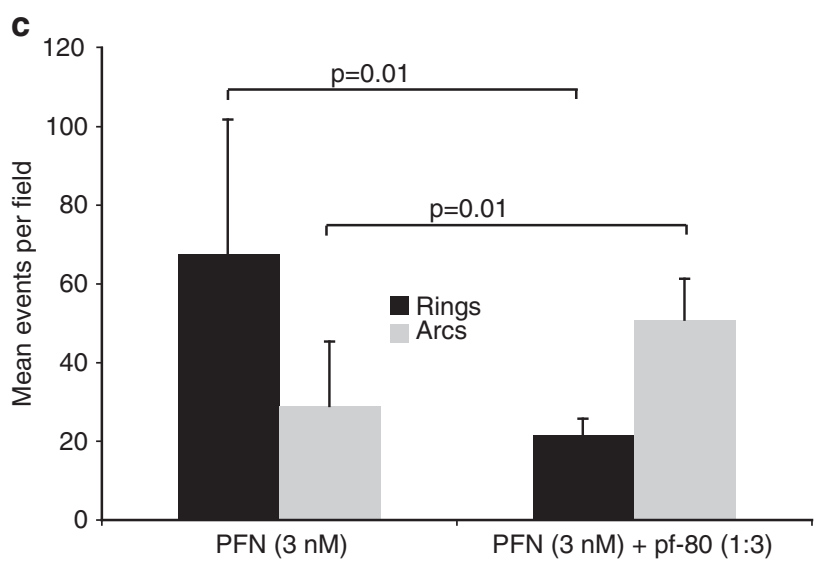

Figure 6 The anti-PFN mAb, pf-80, augments the number of incomplete pores/arcs on PFN treated T24 bladder carcinoma cells. (a and $\mathbf{b})$ : Imaging of structures formed by PFN on T24 using DEEM. (a) PFN (3nM) was added ( $4 \mathrm{~min})$ at $37^{\circ} \mathrm{C}$ to $2 \%$ paraformaldehyde fixed T24 cells. Cells were washed, fixed in $2 \%$ Glutaraldehyde, frozen and deep etched followed by production of platinum replicas and imaging. Rings (arrows) ranged in external diameter from 19 to $34 \mathrm{~nm}$. A small proportion of Arcs were also observed (arrowheads); (b) Fixed T24 cells were treated with pf- 80 ( $9 \mathrm{nM}$ ) followed by PFN ( $3 \mathrm{nM})$. Rings (arrows) and Arcs (arrowheads) are shown. Scale bar $=100 \mathrm{~nm}$. (c) Summary: the number of rings and arcs for PFN alone or PFN:pf-80 at 1:3 molar ratio with PFN constant at $3 \mathrm{nM}$ (mean + S.D.) are shown; Representative of 5-8 fields. A paired $t$-test (2-tailed with two sample unequal variance) was utilized to measure statistical significance 
was clearly detectable after $15 \mathrm{~min}$ with $80 \%$ of vesicles containing the protease after $60 \mathrm{~min}$. and the accumulation of GzmB in GPMVs was augmented by depleting the vesicle membrane of cholesterol. Since both GzmB and many CPPs are highly cationic, it is tempting to speculate that the protease might use analogous mechanisms to cross arc structures.

We use PI to monitor the integrity of target cell plasma membrane in presence of varying PFN concentrations: three subsets are observed whose proportion vary with PFN concentration. ${ }^{36}$ The most important is the $\mathrm{PI}$ negative subset which is divided among cells untouched by PFN and cells that have undergone rapid flip-flop (low annexin- $V+$ ). Currently, annexin- $V$ reactivity appears to be the sole marker for susceptibility to GzmB delivery. ${ }^{36}$ In the absence of PI uptake, we propose that cells contain primarily PFN arcs which direct translocation of the granzymes.

The second subset (PI low) reflects entry of the cationic dye but the fluorophore is bound by cytosolic RNA's resulting in marginal fluorescence. ${ }^{36}$ This population generally is minor and difficult to detect through a range of human PFN concentrations. At present, whether the PI uptake occurs through arcs, repaired pores or both structures is unclear. Nevertheless, this subset is seen during attack by freshly isolated antigen specific mouse CTLs. ${ }^{36}$ Finally, there is the well known PI high subset. Here, embedded pores exceed repair capabilities and the cell dies. The PI readily crosses the plasma and nuclear membrane binding to the nuclear DNA of these necrotic cells.

Why $\mathrm{PI}$ uptake is not observed in low annexin- $\mathrm{V}$ positive cells that are very susceptible to GzmB is uncertain. We suspect, like GzmB, that PI undergoes translocation into these cells. However, due to a low density of arc strucures, a limited number of PI molecules have the opportunity to reach the cytosol and bind to cytosolic RNAs where moderate excitability is below detection by flow cytometry. On the other hand, GzmB translocation is readily detectable because very few molecules are necessary to achieve the death endpoint in the sensitive target cells due to the amplification cascades (Caspase3/7 and/or Bid).

Supporting our earlier model ${ }^{3}$ in which PFN and GzmB undergo co-endocytosis and the granzyme then translocates across the vesicular membrane to the cytosol, ${ }^{3}$ Lieberman and colleagues recently generated CLSM images suggesting that such a pathway is adopted by the granzyme. Nonetheless, the mechanism of translocation remains undefined except to speculate that the protease crosses cylindrical pores embedded in the endosomal surface. ${ }^{1,12}$ The data we present here establishes a refined paradigm that exemplifies the versatility of PFN monomers, being able to form rings and arcs in model and plasma membranes. Further, GzmB delivery clearly operates in a $\mathrm{Ca}^{2+}$ independent manner among the $\mathrm{PI}$ negative/low cells minimizing a role for classical endocytosis. ${ }^{6}$

We have established that granzyme delivery correlates with the presence of arcs on the target cell in vitro. Furthermore, our data show in a more physiological state that an antigenspecific CTL rapidly induce both $\mathrm{PS}$ flip-flop and $\mathrm{PI}_{\text {low }}$ reactivity. ${ }^{6}$ Therefore, after CTL contact, the target cell presumably bears both arcs and cylindrical pores at the site of granule secretion. While cylindrical pores have been considered the entry point for the granzyme, access through these structures may not be optimal because the protease must undergo ion exchange from its carrier, the proteoglycan - serglycin, ${ }^{37,38}$ to a cylindrical pore. Instead, more favorable conditions for translocation of the cationic protease may be offered by a PFN arc which forms a distensible water channel allowing the granzyme to undergo ion exchange through the toroidal pore to the inner leaflet of the target cell.

PFN therefore appears to adopt two functional forms: the endpoint closed cylindrical pore and a series of arciform structures containing an increasing number of monomers. In this model, arcs allow the protected delivery of granzyme while cylinders modulate plasma membrane homeostasis via membrane repair. In a corollary, cylindrical pores may drive endocytosis encouraging uptake of arcs and then translocation of GzmB through the latter internalized structures. ${ }^{10,11}$ Inasmuch as a single uncleared cylindrical pore is sufficient to induce necrotic cell death, ${ }^{39}$ the $\mathrm{Ca}^{2+}$-dependent membrane repair response elicited by these pores would be crucial for cellular homeostasis. PFN is clearly able to form toroidal pores, the gateway for GzmB, which itself, due to its highly cationic state, exploits these water channels to obtain passage. These arcs minimize necrotic predisposition and inadvertent release of pathogens from target cells that cytotoxic effectors encounter. The cylindrical pore versus arc dichotomy must now be taken into account in the understanding of PFN-mediated pathology. Furthermore, the development of novel therapeutics that differentially enhance apoptotic processes mediated by the cytotoxic cell granule secretion pathway warrant serious consideration.

\section{Materials and Methods}

Cell lines and reagents. Jurkat cells, from ATCC, were cultured in RPMI media with $10 \%$ fetal bovine serum (FBS). All reagents and tissue culture supplies were purchased from either Sigma-Aldrich (St Louis, MO, USA) or Invitrogen (Carlsbad, CA, USA). Granzyme B (GzmB) and human perforin (PFN) were isolated as described. ${ }^{40,41}$ 1-palmitoyl-2-oleoyl-sn-glycero-3-phosphocholine (POPC) was purchased from Avanti Polar Lipids (Alabaster, AL, USA). The antiPFN antibody pf-80 was from Mabtech, Sweden.

Calcium influx in PFN treated targets. Jurkat cells preloaded with Fluo3 and Fura Red ( $1 \mu \mathrm{M}$ each) were treated with PFN in presence of PI $(10 \mu \mathrm{g} / \mathrm{ml})$ and flow cytometry data acquired in real-time (Metkar et al., 2011).

PFN induced PS flip-flop in targets measured by Annexin V binding. Cells were treated with designated concentrations of PFN for $15 \mathrm{~min}$ in presence of $\mathrm{Pl}(10 \mu \mathrm{g} / \mathrm{ml})$ in the absence or presence of the pf- 80 (or an isotype matched control) antibody in varying molar ratios, washed and then stained with Ann-V-FITC reagent. ${ }^{6}$

Production of the lethal hit. Target cells were treated with PFN and GzmB in presence or absence of the pf- 80 or isotype matched control antibody. The experiment was carried out either for $60 \mathrm{~min}$ or in case of pulse experiments for $5 \mathrm{~min}$ at $37^{\circ} \mathrm{C}$. ${ }^{6}$ Mitochondrial depolarization was measured as described. ${ }^{42}$

Activation of Caspase3/7. Target cells were treated with PFN and GzmB as described above in presence of the Cell Event Caspase 3/7 detection reagent ( $5 \mu \mathrm{M}$, Invitrogen, Carlsbad, CA, USA), and PI for 5 min (pulse) or continuously for $1 \mathrm{~h}$ incubation at $37^{\circ} \mathrm{C}^{6}$

Kinetics of GzmB and PFN clearance from the plasma membrane. A pulse-chase approach was utilized wherein cells were incubated with $1.92 \mathrm{nM}$ of Alexa 488 tagged native human GzmB in plain RPMI - 0.5\% BSA 
for $30 \mathrm{~min}$ at $4{ }^{\circ} \mathrm{C}$ on ice. After three washes, cells were resuspended at $37^{\circ} \mathrm{C}$ in pre-warmed RPMI/BSA and chased for $0,5,15$ and $30 \mathrm{~min}$ at $37^{\circ} \mathrm{C}$. Residual bound $\mathrm{GzmB}$ was determined by staining with rabbit polyclonal anti-alexafluor488 Ab (anti-488, Molecular Probes, OR, USA) followed by Alexa488 conjugated donkey anti-rabbit Ab (Molecular Probes, OR, USA). For PFN, cells were treated with PFN $(7.6 \mathrm{nM})$ in presence of $0.2 \mathrm{mM} \mathrm{Ca}^{2+}$ containing buffer $(150 \mathrm{mM} \mathrm{NaCl}$, $20 \mathrm{mM}$ Hepes, $\mathrm{pH} 7.4,0.5 \% \mathrm{BSA}$ ) for $30 \mathrm{~min}$ on ice, washed in chilled buffer and chased at $37^{\circ} \mathrm{C}$ in pre-warmed buffer for the times indicated. Cells were then washed and bound PFN was detected on gated, PI negative cells by staining with either an isotype control or the anti-PFN ( $\delta G 9)$ antibody followed by a FITCtagged anti-mouse secondary antibody.

Detection of PFN:pf-80 complex on target cell surface by flow cytometry. Jurkats were treated with PFN $(0$ to $2.3 \mathrm{nM})$ in absence or presence of pf-80 ( 0.25 fold to 3 fold molar excess) or an isotype control antibody ( 1 fold molar excess), washed and stained with an Alexa 488 tagged anti mouse secondary antibody. To investigate whether pf-80 could interfere with PFN binding, cells were coincubated with PFN and pf-80 (0.25 to 1 fold molar excess) or pre-incubated with pf-80 for $15 \mathrm{~min}$ at room temperature. After $10 \mathrm{~min}$, cells were stained with Alexa 488 tagged anti-mouse secondary antibody. To study the effect of $\mathrm{Ca}^{+}{ }^{+}$chelation on binding of PFN:pf-80 complexes to the plasma membrane, PFN $(0-1.7 \mathrm{nM})$ was pre-incubated with pf-80 (1 and 3 fold molar excess) for 15 min followed by introduction of cells. After $10 \mathrm{~min}$, cells were washed in presence or absence of EGTA $(5 \mathrm{mM})$, and stained with Alexa 488 anti-mouse antibody.

In situ Calcium calibration. To calibrate calcium influx by flow cytometry, a series of buffers with known calcium concentrations (Calcium calibration kit, Invitrogen, Carlsbad, CA, USA) were used. ${ }^{43,44}$

\begin{abstract}
Atomic force microscopy with supported planar bilayer preparation on mica. POPC liposomes were prepared as reported. ${ }^{7}$ Mica, glued to a metal disc, was freshly cleaved to obtain smooth surface and a Teflon chamber was stacked on the metal disc with vacuum grease. The LUV suspension was diluted in MilliQ water to a final concentration of $2 \mathrm{mg} / \mathrm{ml}$ in the presence of $2 \mathrm{mM} \mathrm{Ca}^{+2}$ and incubated on mica surface for $30 \mathrm{~min}$ at room temperature. Unattached LUVs were removed by adding a large volume of $1.25 \mathrm{mM} \mathrm{Ca}^{+2}$, $150 \mathrm{mM} \mathrm{NaCl}, 20 \mathrm{~mm}$ Hepes, pH 7.4 buffer. PFN was added at the indicated concentrations in absence or presence of the pf- 80 or isotype control antibody. After 15 min incubation at RT, the sample was carefully washed, Teflon chamber removed leaving approximately $100 \mu \mathrm{l}$ of solution and the sample analyzed by AFM. An Asylum Research Cypher, equipped with a droplet tip holder was used to acquire AFM data in liquid environment. Olympus TR400 and BL-AC40 cantilevers were used in tapping mode, scanning the sample with a scan rate of $\sim 1 \mathrm{~Hz}$. Asylum provided software was used for data acquisition. Image analysis was performed with SPIP (v4.2.6.0), applying line-by-line height compensation.
\end{abstract}

Electrophysiological measurements on Planar Lipid Membranes. Solvent-free PLM were prepared and measurements performed as described. ${ }^{45}$

Deep etch electron microscopy. T24 cells were grown on coverslips and fixed in $2 \%$ paraformaldehyde in $100 \mathrm{mM} \mathrm{NaCl}, 30 \mathrm{mM}$ HEPES, pH 7.2, $2 \mathrm{mM}$ $\mathrm{CaCl}_{2}$ and $150 \mathrm{mM}$ Sucrose (NaHCa-Suc) for $1 \mathrm{~h}$. The coverslips were then washed in Ringer's solution ( $155 \mathrm{mM} \mathrm{NaCl}, 3 \mathrm{mM} \mathrm{KCl}, 2 \mathrm{mM} \mathrm{CaCl}, 1 \mathrm{mM} \mathrm{MgCl}_{2}$, $3 \mathrm{mM} \mathrm{NaH}_{2} \mathrm{PO}_{4}, 5 \mathrm{mM}$ HEPES, pH 7.2 and $10 \mathrm{mM}$ glucose) and $50 \mu$ of the ringer solution placed on each coverslip. PFN $(3 \mathrm{nM})$ was then added to the coverslips and allowed to incubate in a $37^{\circ} \mathrm{C}$ waterbath for $4 \mathrm{~min}$, followed by washes and fixation in $2 \%$ glutaraldehyde in NaHCa-Suc buffer for 30 min. Where the pf- 80 was used, the antibody $(9 \mathrm{nM})$ was added to the coverslip before the addition of PFN. Platinum replicas were prepared as described previously, ${ }^{46}$ examined in a 100CX microscope (JEOL, Peabody, MA, USA) and imaged with an AMT digital camera (Danvers, MA, USA).

Penetration of GzmB into giant plasma membrane vesicles (GPMVs). Rat basophilic leukemia RBL-2H3 cells (ATTC CRL-2256) were cultured in MEM media with $15 \%$ FCS. GPMVs were generated as described earlier. ${ }^{35}$ Briefly, adherent cells were washed with buffer containing $2 \mathrm{mM} \mathrm{CaCl}_{2} ; 150 \mathrm{mM} \mathrm{NaCl} ; 10 \mathrm{mM}$ HEPES (pH 7.4) and incubated in the same buffer supplemented with $2 \mathrm{mM}$ $\mathrm{N}$-ethylmaleimide mildly shaking (300 r.p.m) at $37^{\circ} \mathrm{C}$ for $1,5 \mathrm{~h}$. Supernatant with vesicles was removed, stored on ice and used in experiments on the same day.
GPMVs were imaged with Olympus IX81 inverted microscope equipped with the FluoView1000 confocal system using a $60 \times$ water-immersion objective and excitation at $488 \mathrm{~nm}$ (Alexa Fluor 488), $559 \mathrm{~nm}$ (AF 594) and $635 \mathrm{~nm}$ (AF 647). The lasers were run in a sequential scanning mode to avoid the spectral overlap.

Statistical analysis. A paired $t$-test (2-tailed with two sample unequal variance) was utilized to measure statistical significance.

\section{Conflict of Interest}

The authors declare no conflict of interest.

Acknowledgements. Dr W. Russin \& C. Wilke (Northwestern University) and $\mathrm{Dr}$ C. Sato, (Biomedical Research Institute, Japan) helped with electron microscopy experiments. Dr G-M Mustata, Dr G. Shekhawat and Prof V. Dravid (Northwestern University) participated in the initial atomic force microscopy experiments. MDS and VA thank the Nanosmart Project from the Provincia Autonoma di Trento and the Laboratory of Biomolecular Sequence and Structure Analysis for Health (LaBSSAH) for support. JP was supported by Grant SAF2011-25390 from Spanish Ministry of Economy and Competitiveness. We also thank Sri Raja and Vern Carruthers for their helpful editorial comments.

1. Thiery J, Keefe D, Boulant S, Boucrot E, Walch M, Martinvalet D et al. Perforin pores in the endosomal membrane trigger the release of endocytosed granzyme $B$ into the cytosol of target cells. Nat Immunol 2011; 12: 770-777.

2. Law RH, Lukoyanova N, Voskoboinik I, Caradoc-Davies TT, Baran K, Dunstone MA et al. The structural basis for membrane binding and pore formation by lymphocyte perforin. Nature 2011; 468: 447-451.

3. Froelich CJ, Orth K, Turbov J, Seth P, Babior BM, Gottlieb RA et al. New Paradigm for Lymphocyte Granule Mediated Cytotoxicity: targets bind and internalize granzyme B but a endosomolytic agent is necessary for cytosolic delivery and apoptosis. JBiolChem 1996; 271: 29073-29079.

4. Keefe D, Shi L, Feske S, Massol R, Navarro F, Kirchhausen T et al. Perforin triggers a plasma membrane-repair response that facilitates CTL induction of apoptosis. Immunity 2005; 23: 249-262.

5. Metkar SS, Wang B, Aguilar-Santelises M, Raja SM, Uhlin-Hansen L, Podack E et al. Cytotoxic cell granule-mediated apoptosis: perforin delivers granzyme B-serglycin complexes into target cells without plasma membrane pore formation. Immunity 2002; 16: $417-428$.

6. Metkar SS, Wang B, Catalan E, Anderluh G, Gilbert RJ, Pardo J et al. Perforin rapidly induces plasma membrane phospholipid flip-flop. PLoS One 2012; 6: e24286.

7. Praper T, Sonnen AF, Kladnik A, Andrighetti AO, Viero G, Morris KJ et al. Perforin activity at membranes leads to invaginations and vesicle formation. Proc Natl Acad Sci USA 2012; 108: 21016-21021.

8. Gilbert RJ, Mikelj M, Dalla Serra M, Froelich CJ, Anderluh G. Effects of MACPF/CDC proteins on lipid membranes. Cell Mol Life Sci 2012; 70: 2083-2098.

9. Zuber B, Levitsky V, Jonsson G, Paulie S, Samarina A, Grundstrom S et al. Detection of human perforin by ELISpot and ELISA: ex vivo identification of virus-specific cells. J Immunol Methods 2005; 302: 13-25.

10. Walev I, Bhakdi SC, Hofmann F, Djonder N, Valeva A, Aktories K et al. Delivery of proteins into living cells by reversible membrane permeabilization with streptolysin-O. Proc Natl Acad Sci USA 2001; 98: 3185-3190.

11. Idone V, Tam C, Goss JW, Toomre D, Pypaert M, Andrews NW. Repair of injured plasma membrane by rapid Ca2 + -dependent endocytosis. J Cell Biol 2008; 180: 905-914.

12. Thiery J, Keefe D, Saffarian S, Martinvalet D, Walch M, Boucrot E et al. Perforin activates clathrin- and dynamin-dependent endocytosis, which is required for plasma membrane repair and delivery of granzyme B for granzyme-mediated apoptosis. Blood 2010; 115: 1582-1593.

13. Radosevic K, de Grooth BG, Greve J. Changes in intracellular calcium concentration and $\mathrm{pH}$ of target cells during the cytotoxic process: a quantitative study at the single cell level. Cytometry 1995; 20: 281-289.

14. Praper T, Besenicar MP, Istinic H, Podlesek Z, Metkar SS, Froelich CJ et al. Human perforin permeabilizing activity, but not binding to lipid membranes, is affected by $\mathrm{pH}$. $\mathrm{Mol}$ Immunol 2010; 47: 2492-2504.

15. Aleshin AE, Schraufstatter IU, Stec B, Bankston LA, Liddington RC, Discipio RG. Structure of Complement $\mathrm{C} 6$ suggests a mechanism for initiation and unidirectional, sequential assembly of the Membrane Attack Complex (MAC). J Biol Chem 2012; 287: 10210-10222.

16. Praper T, Sonnen A, Viero G, Kladnik A, Froelich CJ, Anderluh G et al. Human perforin employs different avenues to damage membranes. J Biol Chem 2011; 286: 2946-2955.

17. Raja SM, Metkar SS, Honing S, Wang B, Russin WA, Pipalia NH et al. A novel mechanism for protein delivery: granzyme $B$ undergoes electrostatic exchange from serglycin to target cells. J Biol Chem 2005; 280: 20752-20761. 
18. Lopez JA, Susanto O, Jenkins MR, Lukoyanova N, Sutton VR, Law RH et al. Perforin form transient pores on the target cell plasma membrane to facilitate rapid access of granzymes during killer cell attack. Blood 2013; 121: 2659-2668.

19. Gurtovenko AA, Onike OI, Anwar J. Chemically induced phospholipid translocation across biological membranes. Langmuir 2008; 24: 9656-9660.

20. Sobko AA, Kotova EA, Antonenko YN, Zakharov SD, Cramer WA. Lipid dependence of the channel properties of a colicin E1-lipid toroidal pore. J Biol Chem 2006; 281: 14408-14416.

21. He K, Ludtke SJ, Worcester DL, Huang HW. Neutron scattering in the plane of membranes: structure of alamethicin pores. Biophys J 1996; 70: 2659-2666.

22. Fox Jr RO, Richards FM. A voltage-gated ion channel model inferred from the crysta structure of alamethicin at 1.5-A resolution. Nature 1982; 300: 325-330.

23. Allende D, Simon SA, Mclntosh TJ. Melittin-induced bilayer leakage depends on lipid material properties: evidence for toroidal pores. Biophys J 2005; 88: 1828-1837.

24. Matsuzaki K, Murase O, Fujii N, Miyajima K. An antimicrobial peptide, magainin 2, induced rapid flip-flop of phospholipids coupled with pore formation and peptide translocation. Biochemistry 1996; 35: 11361-11368

25. Alvarez C, Pazos IF, Lanio ME, Martinez D, Schreier S, Casallanovo F et al. Effect of pH on the conformation, interaction with membranes and hemolytic activity of sticholysin II, a pore forming cytolysin from the sea anemone Stichodactyla helianthus. Toxicon 2001; 39 : 539-553.

26. Anderluh G, Dalla Serra M, Viero G, Guella G, Macek P, Menestrina G. Pore formation by equinatoxin II, a eukaryotic protein toxin, occurs by induction of nonlamellar lipid structures. J Biol Chem 2003; 278: 45216-45223.

27. Sonnen AF, Plitzko JM, Gilbert RJ. Incomplete pneumolysin oligomers form membrane pores. Open Biol 2014; 4: 140044.

28. Sobko AA, Kotova EA, Antonenko YN, Zakharov SD, Cramer WA. Effect of lipids with different spontaneous curvature on the channel activity of colicin E1: evidence in favor of a toroidal pore. FEBS Lett 2004; 576: 205-210.

29. Epand RF, Martinou JC, Montessuit S, Epand RM, Yip CM. Direct evidence for membrane pore formation by the apoptotic protein Bax. Biochem Biophys Res Commun 2002; 298 744-749.

30. Stoddart D, Ayub M, Hofler L, Raychaudhuri P, Klingelhoefer JW, Maglia G et al. Functiona truncated membrane pores. Proc Natl Acad Sci USA 2014; 111: 2425-2430.

31. Dunstone MA, Tweten RK. Packing a punch: the mechanism of pore formation by cholesterol dependent cytolysins and membrane attack complex/perforin-like proteins. Curr Opin Struct Biol 2012; 22: 342-349.

32. Praper T, Besenicar MP, Istinic H, Podlesek Z, Metkar SS, Froelich CJ et al. Human perforin permeabilizing activity, but not binding to lipid membranes, is affected by $\mathrm{pH}$. Mol Immunol 47: 2492-2504.
33. Duchardt F, Fotin-Mleczek M, Schwarz H, Fischer R, Brock R. A comprehensive model for the cellular uptake of cationic cell-penetrating peptides. Traffic 2007; 8: 848-866.

34. Fretz MM, Hogset A, Koning GA, Jiskoot W, Storm G. Cytosolic delivery of liposomally targeted proteins induced by photochemical internalization. Pharm Res 2007; 24: 2040-2047.

35. Saalik P, Niinep A, Pae J, Hansen M, Lubenets D, Langel U et al. Penetration without cells: membrane translocation of cell-penetrating peptides in the model giant plasma membrane vesicles. J Control Release 2011; 153: 117-125.

36. Metkar SS, Wang B, Catalan E, Anderluh G, Gilbert RJ, Pardo J et al. Perforin rapidly induces plasma membrane phospholipid flip-flop. PLoS One 6: e24286.

37. Raja SM, Wang B, Dantuluri M, Desai UR, Demeler B, Spiegel K et al. Cytotoxic cell granule-mediated apoptosis. Characterization of the macromolecular complex of granzyme B with serglycin. J Biol Chem 2002; 277: 49523-49530.

38. Martina JA, Wu XS, Catalfamo M, Sakamoto T, Yi C, Hammer JA 3rd. Imaging of lytic granule exocytosis in CD8 + cytotoxic T lymphocytes reveals a modified form of full fusion. Cell Immunol 2011; 271: 267-279.

39. Peters R, Sauer H, Tschopp J, Fritzsch G. Transients of perforin pore formation observed by fluorescence microscopic single channel recording. EMBO J 1990; 9: 2447-2451.

40. Froelich CJ, Turbov J, Hanna W. Human perforin: rapid enrichment by immobilized metal affinity chromatography (IMAC) for whole cell cytotoxicity assays. Biochem Biophys Res Commun 1996; 229: 44-49.

41. Hanna WL, Zhang X, Turbov J, Winkler U, Hudig D, Froelich CJ. Rapid purification of cationic granule proteases: application to human granzymes. Protein Expr Purif 1993; 4: 398-404.

42. Metkar SS, Wang B, Ebbs ML, Kim JH, Lee YJ, Raja SM et al. Granzyme B activates procaspase- 3 which signals a mitochondrial amplification loop for maximal apoptosis. $J$ Cell Biol 2003; 160: 875-885.

43. Chused TM, Wilson HA, Greenblatt D, Ishida Y, Edison LJ, Tsien RY et al. Flow cytometric analysis of murine splenic $B$ lymphocyte cytosolic free calcium response to anti-lgM and anti-lgD. Cytometry 1987; 8: 396-404.

44. Li Q, Altschuld RA, Stokes BT. Quantitation of intracellular free calcium in single adult cardiomyocytes by fura-2 fluorescence microscopy: calibration of fura-2 ratios. Biochem Biophys Res Commun 1987; 147: 120-126.

45. Dalla Serra M, Menestrina G. Liposomes in the study of pore-forming toxins. Methods Enzymol 2003; 372: 99-124.

46. Keyel PA, Loultcheva L, Roth R, Salter RD, Watkins SC, Yokoyama WM et al. Streptolysin $O$ clearance through sequestration into blebs that bud passively from the plasma membrane. J Cell Sci 2012; 124(Pt 14): 2414-2423.

Supplementary Information accompanies this paper on Cell Death and Differentiation website (http://www.nature.com/cdd) 